\title{
Uma experiência de Orientação Profissional com Jogos por meio do GamIFique
}

\author{
Yane Ferreira Machado ${ }^{1}$, Francisco Kelsen de Oliveira $^{1}$ \\ ${ }^{1}$ Instituto Federal de Educação, Ciência e Tecnologia do Sertão Pernambucano (IF \\ Sertão -PE) \\ CEP: 56000-000 Salgueiro, PE - Brasil \\ yaneferreirapsi@gmail.com, francisco.oliveira@ifsertao-pe.edu.br
}

\begin{abstract}
This article aims to present the use of gamification strategies in vocational guidance processes with integrated high school students. The research methodology involved data collection through systematic literature review, document analysis, interviews, focus group, questionnaires, development of a gamified artifact and composition of a professional guidance model. As a result, the participants were able to experience the professional reality of the area they study, mediated through the challenges of the game. The combination of these strategies proved to be feasible to provoke the exploratory behavior of students and increase their knowledge about the professional area they study.
\end{abstract}

Resumo. Este artigo tem o objetivo de apresentar a utilização de estratégias de gamificação em processos de orientação profissional com estudantes do ensino médio integrado. A metodologia de pesquisa envolveu coleta de dados através de revisão sistemática de literatura, análise documental, entrevistas, grupo focal, questionários, desenvolvimento de um artefato gamificado e composição de um modelo de orientação profissional. Como resultados, os participantes puderam vivenciar a realidade profissional da área que estudam, mediados através dos desafios do jogo. A combinação dessas estratégias mostrou-se viável para provocar o comportamento exploratório dos estudantes e ampliar o conhecimento destes sobre a área profissional que estudam.

\section{Introdução}

Este trabalho apresenta um recorte de uma pesquisa que foi desenvolvida com o intuito de propor a utilização de estratégias de gamificação em processos de Orientação Profissional (OP), e assim criar uma metodologia de trabalho em OP mais envolvente e capaz de engajar os participantes. A ideia de desenvolver uma metodologia dessa natureza surgiu com a necessidade de utilizar abordagens mais envolventes e com situações mais próximas da realidade profissional, para o trabalho junto aos jovens nativos digitais, que apresentam formas de aprender, pensar e se comportar diversas em relação às gerações anteriores.

No caso desta pesquisa, a investigação e desenvolvimento metodológico da OP foi direcionada para estudantes de ensino médio integrado a cursos profissionalizantes, de modo a contribuir para uma experiência capaz de aproximar os jovens dos desafios e 
da realidade de atuação na área em que eles estão se profissionalizando, bem como facilitar a conexão e compreensão das dinâmicas profissionais e do mundo do trabalho.

Nas áreas da educação e da psicologia, o trabalho de orientação profissional costumeiramente fez uso de instrumentos que auxiliam no processo de autoconhecimento dos estudantes. No entanto, apesar desses instrumentos fornecerem informações valiosas sobre áreas de interesse e identificação, parece ainda existirem dificuldades em relação à interlocução dos achados que esses instrumentos produzem com questões mais externas aos orientandos. Assim, podem ocorrer limitações no tocante ao aproveitamento da OP para o amadurecimento desses jovens em relação ao conhecimento e compreensão sobre o mundo do trabalho e a atuação na prática profissional.

Nesse sentido, a utilização de estratégias de gamificação dentro de um processo de orientação profissional teve como objetivo tornar a OP mais vivencial, capaz de envolver e engajar os participantes e trazer para eles experiências mais próximas da realidade profissional, constituindo-se assim uma experimentação quanto à viabilidade deste recurso metodológico, a qual será melhor relatado ao longo do trabalho.

\section{A gamificação como estratégia de inovação e aprimoramento em processos de orientação profissional}

A Orientação Profissional tal como compreendemos no século XXI é fruto de uma concepção relativamente nova acerca deste processo e das variáveis nele envolvidas. Pesquisas remontam que antes de despertar o interesse de áreas como a Educação e a Psicologia, a versão embrionária da OP era concebida como um aconselhamento ou ajuda e estava baseada em concepções religiosas e filosóficas, e há ainda quem remeta o início da preocupação com as ocupações profissionais a pensadores da Grécia antiga, como Aristóteles e Platão [Tavares 2009].

Segundo Bock [2013], a questão da escolha profissional só passou a ganhar espaço e fazer sentido com o advento do capitalismo. A partir desse período, o trabalhador encontra-se desprovido de meios de produção e vê-se impelido a vender sua força de trabalho. O empregador, por sua vez, interessa-se por essa força de trabalho no intuito de produzir excedentes que possam gerar lucros. Com as revoluções industriais e a divisão técnica do trabalho, a tarefa de produzir torna-se mais complexa, e portanto, as escolhas profissionais passam a ter importância para direcionar de forma eficaz a força de trabalho em uma sociedade capitalista.

Podemos dizer que a perspectiva atual sobre a orientação profissional evoluiu da concepção inatista, na qual o sujeito teria uma vocação pré-determinada, para a visão desenvolvimentista [Zatti et al. 2017; Munhoz, Melo-Silva e Audibert 2016]. Nesses termos, a OP passou a ser compreendida como um processo que acontece ao longo da vida, considerando que, diante de mudanças nos papéis sociais, novas escolhas podem ocorrer, bem como o surgimento de outras inclinações profissionais.

Como uma das principais premissas adotadas na sua experiência com orientação profissional, Lisboa [2017] aponta ser importante que esse processo sirva para estimular o sujeito a refletir sobre suas características e demais elementos que influenciam nas escolhas da vida profissional. Para a autora, o orientador assume o papel de incentivar a reflexão do orientando sobre sua identidade individual e o significado do trabalho que é executado, seja para ele próprio ou para os outros. Em outras palavras, os atores 
envolvidos no processo assumem um papel de construção de um entendimento, tanto do orientando e das influências para sua escolha, como da identidade profissional.

Outro aspecto importante de ser assinalado é a perspectiva sócio-histórica em OP que permeia essa pesquisa, a qual considera o ser humano como multideterminado e busca entender dialeticamente o indivíduo na sua relação com a sociedade [Bock 2013]. Nessa abordagem, há entendimento de que a escolha profissional não nasce de uma aptidão inata, sendo construída através de arranjos sociais e culturais nos quais o sujeito está imerso. Por tanto, é um processo dinâmico e mutável. Percebendo-o dessa forma, Oliveira [2016] defende que a OP pode ser realizada nas escolas, principalmente com adolescentes, enfocando a possibilidade de trabalhar de forma ativa, envolvendo os professores e outros agentes da comunidade escolar no processo de escolha profissional do estudante.

Esse cenário permite que a gamificação entre em cena e traga contribuições significativas. A gamificação que tem sido trabalhada como estratégia de apoio à aprendizagem em instituições como escolas, universidades, empresas, entre outras e tem se mostrado capaz de se adequar a contextos e temáticas variadas, como mostram as experiencias de Almeida et al. [2016], Silva et al.[2017] Silva, Sales e Castro [2018] e Terçariol et al. [2018].

Nas palavras de Jorge e Sutton [2016, p. 104], a gamificação trata-se de "uma estratégia holística, capaz de engajar os indivíduos organizacionais até fora dos limites do ambiente interno das organizações". Os autores apontam que a gamificação vai ao encontro de características das gerações que nasceram e cresceram em contato maior com a tecnologia, uma vez que a familiaridade com essas ferramentas resulta em mudanças comportamentais.

Voltando a atenção para o contexto educacional, Massi [2017] sugere o uso de jogos na educação como uma estratégia para manter os aprendizes envolvidos e motivados, já que o ambiente lúdico cria o envolvimento necessário para que os jogadores se sintam desafiados e busquem testar e desenvolver suas habilidades.

A gamificação permite inovar as metodologias de ensino "criando espaços de aprendizagem mediados pelo desafio, pelo prazer e entretenimento, proporcionando graus de imersão e diversão que dificilmente são atingidos pelos métodos tradicionais" [Massi 2017, p. 20]. Esse tipo de intervenção permite que o sujeito interaja e se relacione de forma ativa com o que se espera dele em relação à aprendizagem, e é essa forma de interação prazerosa e capaz de provocar a imersão, que se espera da combinação da OP com gamificação.

No entendimento de Busarello [2016, p.28] a gamificação "não se limita apenas à utilização das mecânicas de jogos, mas contempla a utilização destas para a resolução de problemas e para a motivação e o engajamento de um público determinado". Em outras palavras, a estratégia compreende a utilização dos elementos que podem estar presentes em jogos e que se mostram mais eficientes para o engajamento e envolvimento do público-alvo. Esses elementos podem ser contemplados no modelo MDA (do inglês Mechanics, Dynamics e Aesthetics) de Hunicke, LeBlanc e Zubek [2004]. Quando combinadas adequadamente, a mecânicas, dinâmica e estética podem produzir os resultados desejados com o uso da gamificação. 
A utilização de Gamificação pode ser um elemento a mais para contribuir com essa integração, agregando elementos que tornam a experiência do processo de OP mais próxima da realidade, como por exemplo, por meio de desafios, competições, simulações e experiências de imersão.

Nesse sentido, a gamificação como estratégia de apoio na OP pode ser uma outra maneira para gerar um ambiente lúdico, dinâmico e tornar o processo mais vivencial, um espaço de simulação onde o estudante poderá experimentar e desenvolver papéis profissionais em um ambiente controlado. A possibilidade de vivenciar diferentes situações durante a realização de um percurso, seja no jogo ou na carreira profissional, pode trazer muitos ensinamentos, especialmente a experiência, e em ambos podem ser seguidos diferentes caminhos para se chegar ao objetivo almejado.

Essa experiência através do jogo e da incorporação de papéis profissionais, aproxima os sujeitos da realidade e pode agregar mais maturidade às decisões tomadas daquele momento em diante. Busarello [2016, p.39] reforça isso ao dizer que na gamificação, "o foco está nas pequenas conquistas para se chegar a um objetivo maior, este fator pode ser multiplicado em variados caminhos, e estes podem ter como fundamento as habilidades, as atitudes e outras características dos alunos. O importante é não perder o foco no objetivo principal". Desta feita, o desafio da proposta metodológica de orientação profissional com gamificação é agregar os elementos da gamificação a intervenções, de modo a permitir a ampliação do autoconhecimento, o desenvolvimento das escolhas profissionais, o reconhecimento de inclinações e a reflexão sobre a identidade profissional entre os estudantes.

A ideia da utilização dessa proposta não é reforçar a aderência dos estudantes na área de estudo dos orientandos, mas sim provocar a reflexão e avaliação sobre a questão profissional de forma mais ampla, enquanto uma realização pessoal, econômica e social para os orientandos, os quais poderão reunir a partir dessa e de outras experiências, elementos para embasar suas escolhas e decidirem quando necessários, sobre a atuação na área em que estão se profissionalizando ou não.

Em outros termos, a experiência proposta foi de imersão em desafios e cenários da área profissional, a qual deve funcionar como uma simulação ou antecipação de aspectos que compõe a profissão elencada para o trabalho de OP, e o orientando terá nesse processo a oportunidade de experienciar o papel de profissional e avaliar o quanto a atuação na área lhe parece algo atrativo ou aversivo. $O$ intuito não é convencer o estudante a permanecer na área em que está se profissionalizando, mas sim instigá-lo a conhecer mais sobre ela e a buscar mais elementos para a tomada de decisão consciente e fundamentada, o que faz parte do comportamento exploratório na orientação profissional.

\section{Metodologia}

A abordagem adotada na pesquisa foi de natureza quanti-quali, de caráter descritivo e exploratório [Appolinário 2016]. Adotou-se um recorte transversal para a pesquisa, cujo intuito foi analisar a viabilidade do uso das estratégias da gamificação em um processo de orientação profissional em grupo realizado com estudantes do $1^{\circ}$ e $3^{\circ}$ anos do Ensino Médio Integrado (EMI) ao curso Técnico em Edificações.

Essa investigação foi desenvolvida a partir das seguintes etapas de coleta de dados: revisão sistemática de literatura, entrevistas com sete docentes e profissionais 
que atuam no curso Técnico em Edificações no Instituto Federal de Educação, Ciência e Tecnologia do Ceará (IFCE), análise de documentos legais (leis, decretos) relacionados à atuação e regulamentação da profissão de Técnico em Edificações e de Normas Regulamentadoras e Técnicas que norteiam a atuação deste profissional na área da construção civil, desenvolvimento de um protótipo e aplicação piloto do jogo GamIFique com duas estudantes egressas do curso, grupo focal com os estudantes do $1^{\circ}$ e $3^{\circ}$ anos do ensino médio integrado ao referido curso, aplicação de questionários de sondagem e de percepção da intervenção, e a implementação do processo de OP com gamificação propriamente dito, aplicado aos dezoito estudantes que se voluntariaram a participar da pesquisa.

Os participantes foram selecionados por meio de amostragem por conveniência, em que os mesmos manifestaram, por escrito, concordância em participar voluntariamente da pesquisa, mediante Termo de Consentimento Livre e Esclarecido assinado pelos participantes adultos, e o Registro de Assentimento Livre e Esclarecido assinado pelos pais ou responsáveis autorizando a participação. Ressaltamos ainda que a realização desta pesquisa foi aprovada pelo Comitê de Ética em Pesquisa do IF Sertão PE mediante o parecer $\mathrm{n}^{\mathrm{o}} 3.360 .633$.

No Quadro 1 temos a síntese dos objetivos almejados com a aplicação dos instrumentos de coleta utilizados na pesquisa:

\section{Quadro 1. Instrumentos de coleta empregados com os sujeitos da pesquisa e} seus objetivos

\begin{tabular}{|c|c|c|c|}
\hline $\begin{array}{l}\text { Fase da } \\
\text { Pesquisa }\end{array}$ & $\begin{array}{c}\text { Instrumento de } \\
\text { Coleta }\end{array}$ & $\begin{array}{l}\text { Sujeitos da } \\
\text { Pesquisa }\end{array}$ & Objetivo \\
\hline \multirow[t]{2}{*}{$\begin{array}{c}\text { Pré- } \\
\text { intervenção }\end{array}$} & $\begin{array}{l}\text { Entrevista } \\
\text { semiestruturada }\end{array}$ & $\begin{array}{l}\text { Servidores } \\
\text { Docentes e } \\
\text { Técnico- } \\
\text { Administrativ } \\
\text { os, monitores } \\
\text { de disciplinas } \\
\text { práticas }\end{array}$ & $\begin{array}{l}\text { Coletar informações sobre as atribuições do profissional } \\
\text { técnico em edificações, rotina laboral, mercado de } \\
\text { trabalho, característica dos profissionais egressos, entre } \\
\text { outros, para levantamento dos requisitos e narrativa do } \\
\text { jogo. }\end{array}$ \\
\hline & $\begin{array}{l}\text { Aplicação Piloto do } \\
\text { Jogo GamIFique }\end{array}$ & $\begin{array}{l}\text { Egressos do } \\
\text { EMI ao } \\
\text { Curso } \\
\text { Técnico em } \\
\text { Edificações } \\
\end{array}$ & $\begin{array}{l}\text { Avaliar a adequação das regras de aplicação, tempo para } \\
\text { resposta, compreensão da linguagem empregada, grau de } \\
\text { dificuldade etc., no intuito de promover as adaptações } \\
\text { necessárias antes da aplicação oficial. }\end{array}$ \\
\hline Intervenção & $\begin{array}{l}\text { Questionários de } \\
\text { Escolha } \\
\text { reconhecimento da } \\
\text { identidade } \\
\text { profissional - parte } \\
\text { 1; Questionário } \\
\text { Socioeconômico; } \\
\text { Aplicação do Jogo } \\
\text { GamIFique; }\end{array}$ & \multirow{2}{*}{$\begin{array}{l}\text { Estudantes do } \\
1^{\circ} \text { e } 3^{\circ} \text { anos } \\
\text { do EMI ao } \\
\text { Curso } \\
\text { Técnico em } \\
\text { Edificações }\end{array}$} & \multirow{2}{*}{$\begin{array}{l}\text { Coletar informações sobre fatores influenciadores na } \\
\text { escolha do curso na área da construção civil, avaliação } \\
\text { dos estudantes sobre a escolha feita, nível de interesse e } \\
\text { motivação dos estudantes para a permanência na área, } \\
\text { conhecimento sobre as atribuições, oportunidades e } \\
\text { desafios do profissional técnico em edificações e de } \\
\text { aplicação dos conhecimentos e técnicas da construção } \\
\text { civil, perspectiva dos estudantes em relação a } \\
\text { permanência na área, identificação de requisitos } \\
\text { necessários para desenvolver um processo de orientação } \\
\text { profissional com gamificação para os estudantes e } \\
\text { avaliar o impacto e aceitação dessa proposta entre os } \\
\text { estudantes. }\end{array}$} \\
\hline $\begin{array}{l}\text { Pós- } \\
\text { intervenção }\end{array}$ & $\begin{array}{l}\text { Questionário de } \\
\text { Escolha } \\
\text { reconhecimento da } \\
\text { identidade } \\
\text { profissional - parte } \\
\text { 2; Questionário de } \\
\text { Percepção Follow } \\
\text { Up. }\end{array}$ & & \\
\hline
\end{tabular}


A análise dos dados coletados teve início com o estudo documental de leis e decretos relacionados a profissão do Técnico em Edificações, bem como da ementa do curso ofertado na instituição lócus da Pesquisa. Com isso, compreender as principais características da atuação desse profissional, os cenários em que ele pode atuar e as normas que regulamentam essa atividade. Seguimos com a análise do material coletado através das entrevistas e do grupo focal com a aplicação da técnica de Análise de Conteúdo [Bardin 1977]. Já os dados provenientes da aplicação de questionários foram analisados com base na Estatística Descritiva e tratados através do software editor de planilhas Excel, para obtermos uma comparação das respostas dos estudantes antes e após o processo de orientação profissional com gamificação, e, dessa forma também foi possível apresentarmos os resultados através de gráficos e percentuais.

\section{Resultados}

Os resultados dessa pesquisa deram origem a uma metodologia de orientação profissional, que como proposto, utilizou elementos da gamificação, conforme Machado [2020]. O desenvolvimento desta abordagem metodológica mostrou-se necessária para tentar preencher lacunas em relação ao desenvolvimento de estratégias mais envolventes e engajadoras para os orientandos, capazes de instrumentalizar e empoderar esses sujeitos para uma leitura crítica da realidade, habilitando-os a identificar suas inclinações profissionais e contribuindo para escolhas mais satisfatórias no âmbito profissional.

Essa metodologia de trabalho em OP materializou-se em duas partes com características hipertextuais (jogo) e textuais (manual de utilização). Optou-se pela apresentação através de dois instrumentos em virtude das características híbridas que a metodologia possui.

A primeira parte consistiu no GamIFique - Orientação profissional com Jogos. Trata-se de um jogo com perguntas e desafios relacionados com as atribuições do técnico em edificações. Esse artefato apresenta duas versões, sendo uma para os estudantes do $1^{\circ}$ ano do curso e a outra direcionado para os discentes do $3^{\circ}$ ano. Ambos estão disponíveis para acesso no site do jogo através do link https://sites.google.com/ifsertao-pe.edu.br/gamifique. O artefato reuniu elementos da gamificação, tais como: dinâmica, estética e mecânica de jogo. Lançamos mão desses elementos para tornar o processo de OP mais envolvente e próximo da realidade profissional.

A segunda parte desta metodologia de OP consiste em um Manual de utilização do jogo e roteiro para desenvolvimento de processos de Orientação Profissional com Gamificação. Nesta produção, constam as instruções de aplicação, pontuação, recompensas, materiais utilizados, perguntas e desafios, e suas respectivas respostas. $\mathrm{O}$ roteiro de aplicação e a estruturação básica do processo de orientação profissional também foram disponibilizados.

O jogo GamIFique foi desenvolvido em três fases, com nível crescente de complexidade. A primeira fase apresentou oito perguntas de múltipla escolha, com opção única de resposta e um minuto para resolução. A segunda fase apresentou questionamentos mistos, sendo quatro perguntas objetivas e dois desafios. Na terceira fase o nível de complexidade foi maior, com questões apenas no formato de desafios, totalizando quatro nessa fase final. $\mathrm{O}$ tempo estipulado para a resposta variou entre um 
minuto para respostas de múltipla escolha, cinco minutos para desafios intermediários e quinze minutos para o desafio final.

Optamos por desenvolver o artefato em três fases para que os jogadores pudessem ter uma experiência progressiva de integração, possibilitando a inserção e adaptação às regras de funcionamento do jogo. Conforme comenta Busarello [2016, p.98)], esses momentos iniciais "(...) tem o intuito de cativar e encorajar o indivíduo a permanecer dentro de um sistema em princípio desconhecido. Os benefícios de se acertar neste processo podem garantir o engajamento em longo prazo." O estabelecimento de fases (ou divisas) também funciona como elementos simbólicos, que marcam o progresso no jogo e incentivam a ideia de promoção dentro do sistema estabelecido [Busarello 2016].

Assim, a fase 01 funcionou como uma forma de aquecimento e de promoção do entrosamento entre os participantes, familiarizando-os com o processo de OP, regras do jogo, membros das equipes, entre outros. As perguntas desenvolvidas para esta fase abordaram assuntos introdutórios na formação do técnico em edificações e da atuação na construção civil, como por exemplo, saúde e segurança nos canteiros de obras, materiais da construção civil e implantação de obras.

A fase 02 procurou manter o engajamento e aumentar a emoção dos participantes com a performance em construção, reforçando a sensação de estarem desempenhando o papel de um profissional. Nessa fase foram apresentados questionamentos sobre assuntos que os estudantes já haviam visto na formação, mas desta vez, esses conteúdos foram expostos em forma de problemas práticos. Os jogadores foram estimulados, por exemplo, a oferecerem soluções e desenvolverem argumentos para justificar a adoção de determinados materiais e recursos em um contexto de negociação com clientes.

A fase 03 mostrou-se a etapa mais envolvente e emocionante para os jogadores. Eles puderam sentir o papel de técnico em edificações de forma mais efetiva, uma vez que a fase apresentou exclusivamente desafios com situações-problemas, nas quais várias atribuições, espaços de atuação, conhecimentos e habilidades do profissional foram articulados, de modo que as equipes puderam construir soluções práticas, como se estivessem no exercício da profissão. Abaixo a Figura 1 mostra o exemplo dos desafios propostos aos orientandos: 


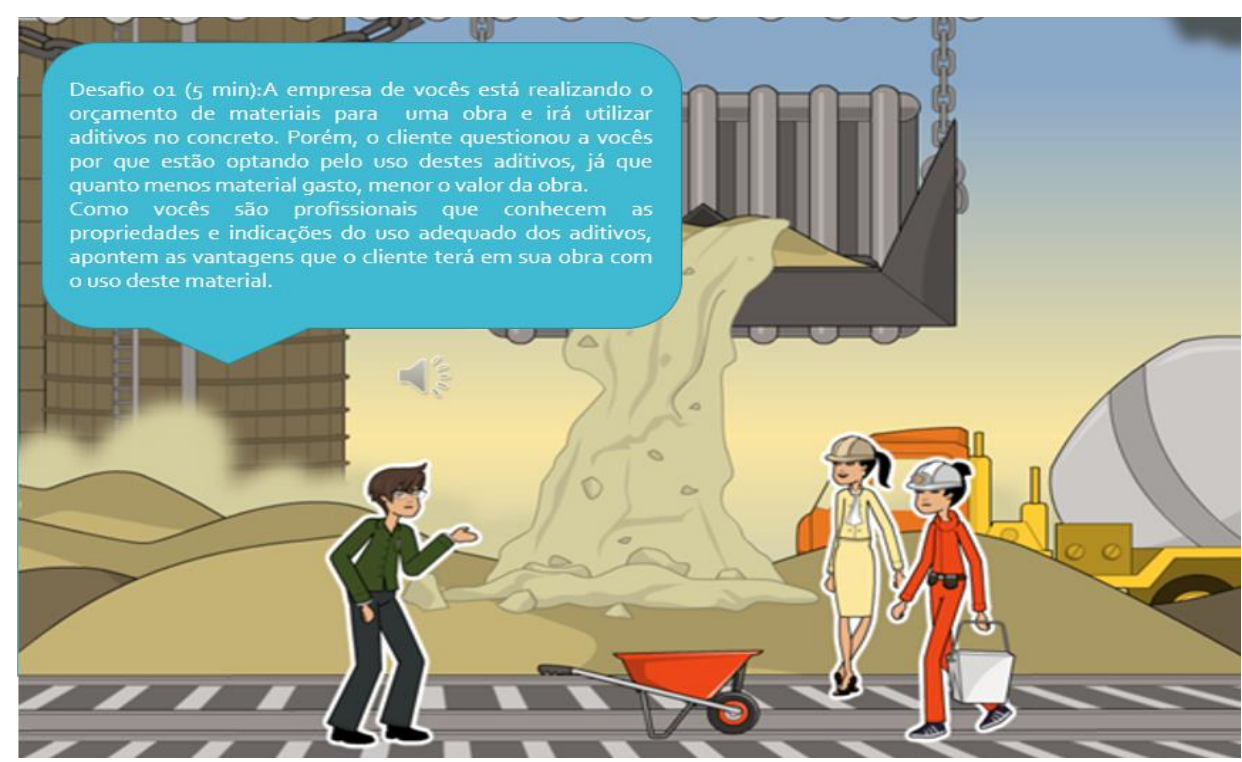

Figura 1. Captura de imagem do jogo GamIFique- orientação profissional com jogos, que mostra um exemplo de desafio proposta aos orientandos

Como assinalado anteriormente, a pesquisa também procurou identificar quantitativamente o impacto desta metodologia de OP com gamificação para os participantes. Em uma análise com base nos dados coletados previamente e após a aplicação do processo de OP com os estudantes do $1^{\circ}$ e $3^{\circ}$ ano do ensino médio, foi possível identificar que, mesmo em períodos distintos do curso e com diferentes níveis de conhecimento sobre a área de formação, os participantes passaram a ter uma compreensão mais realista da profissão de Técnico em Edificações e da atuação na área da construção civil. A seguir temos o Gráfico 1 que mostra a compreensão sobre a profissão que os estudantes tinham antes e depois do processo de OP:

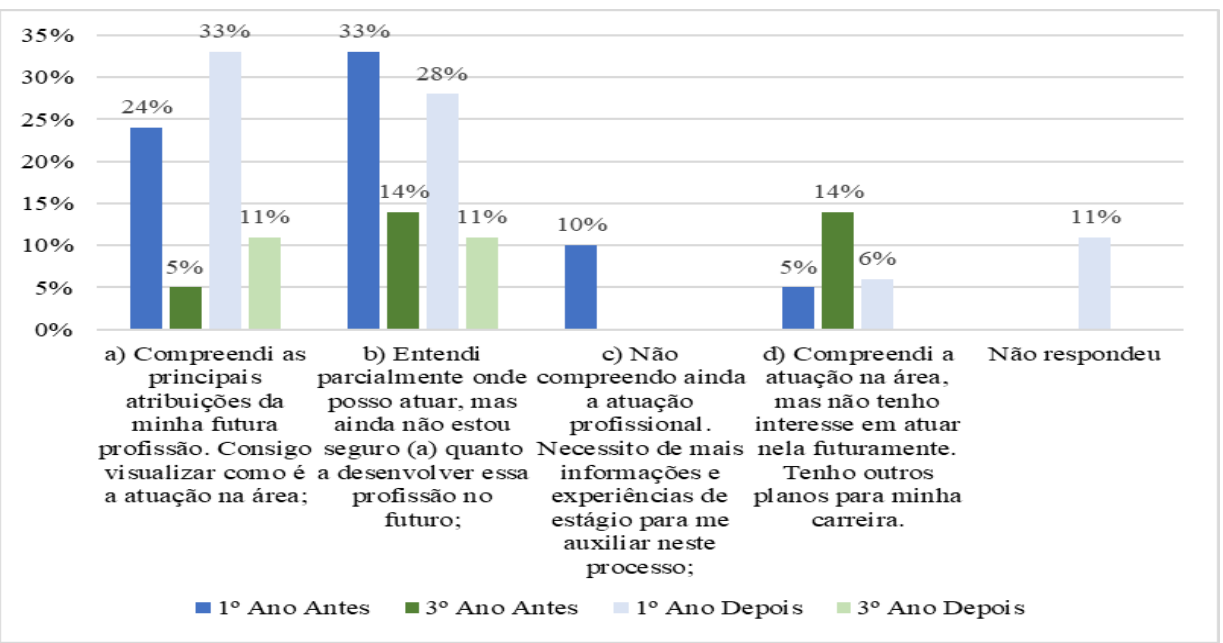

\section{Gráfico 1. Compreensão dos estudantes sobre a profissão do Técnico em Edificações - comparação antes e depois da intervenção}

Esses achados indicam que o processo de orientação profissional com gamificação foi capaz de fornecer informações de maneira consistente, possibilitando aos participantes enxergar melhor a formação que estão tendo e a atuação profissional 
como algo mais real e palpável, um papel futuro que puderam antecipar e experimentar através do jogo.

Em conformidade com a compreensão da abordagem sócio-histórica e sua leitura dialética da realidade, o processo de desenvolvimento da identidade, escolha e desenvolvimento profissional ocorre a partir do que o sujeito vive e internaliza [BOCK, 2013], reforçando assim o seu caráter histórico e dinâmico. Assim, pode-se dizer que a experiência do processo de OP com gamificação trouxe contribuições válidas dentro da perspectiva teórica adotada, uma vez que através da imersão prática provocada por meio dos desafios do jogo GamiIFique, ocorreram repercussões sobre a percepção dos estudantes no tocante à área de formação e em relação a eles mesmos, uma vez que os participantes ampliaram o horizonte de informações sobre a profissão, mostraram-se mais empoderados e seguros em relação ao que pensavam e sentiam sobre o curso, conforme mostraram os resultados apresentados anteriormente.

Observou-se que aqueles que se sentiam atraídos pelo curso técnico em edificações e pela construção civil, tiveram após a experiência, mais condições de mensurar, apontar e identificar elementos da área que os estimulava a querer continuar nela. Do mesmo modo, entre aqueles que a rejeitavam, a experiência vivida contribuiu para clarificar melhor os motivos de não terem afinidade com a construção civil. Alguns desses participantes indicaram que, apesar de não quererem continuar a estudar ou trabalhar na área em que estão se profissionalizando, puderam identificar que a formação trouxe contribuições. Esse autoconhecimento e o conhecimento da área de atuação são igualmente importantes, pois fazem com que o sujeito possa tomar decisões futuras pautadas em uma base sólida e seja capaz de fazer leituras adequadas do mundo do trabalho, da realidade social e de si mesmo.

\section{Considerações Finais}

Apesar dos resultados positivos em relação a metodologia de OP proposta, a ética no uso da gamificação é um aspecto que precisa estar presente em todas as intervenções que fazem uso deste recurso e precisa ser discutida, a fim de evitar abusos e deturpações nas contribuições que a estratégia pode oferecer. O cuidado com os princípios e valores humanos precisa ser resguardado e levados em consideração da criação até a aplicação de experiências que envolvam essa estratégia, sobretudo quando direcionado a sujeitos em fase crítica de desenvolvimento, como as crianças e adolescentes.

Não obstante, é necessário valorizar a importância que as dimensões educação e trabalho têm para o desenvolvimento pessoal dos jovens em processo de construção e reconhecimento de suas habilidades, competências e fragilidades é, portanto, perceber o quanto a juventude é atravessada pelas demandas que emergem desses âmbitos e das quais não pode se desvincular.

Assim, defendemos que a orientação profissional seja utilizada como um recurso para facilitar o envolvimento e empoderamento dos estudantes, atuando como instrumento para a percepção do sentido dessa ação e do pertencimento do estudante dentro do seu processo de formação, auxiliando-o a clarificar suas inclinações profissionais. Além disso, a OP deve ser também um espaço que propicie reflexões e gere, consequentemente, no estudante, o seu amadurecimento para que, quando for preciso fazer escolhas e adotar posicionamentos em relação à sua carreira, o faça de forma consciente. Esperamos que essa metodologia de orientação profissional com 
gamificação possa ser experimentada, avaliada e ampliada para outros públicos e sirva de inspiração para outras investigações que ampliem o conhecimento sobre a orientação profissional e as possibilidades de uso da gamificação em contextos variados.

\section{Referências}

Almeida, C. et al. (2016) “Avaliação do processo de Gamificação acerca do tema Direitos Humanos.” In: Anais do XXII Workshop de Informática na Escola p.379386.

Appolinário, F. (2016) "Metodologia da Ciência: filosofia e prática da pesquisa." (2a Ed.) São Paulo: Cengage Learning.

Bardin, L. (1977) “Análise de Conteúdo”. São Paulo: Edições 70.

Bock, S. D. (2013) “Orientação Profissional: a abordagem sócio-histórica.” (1ª Ed.) São Paulo: Cortez.

Busarello, R. I. (2016) “Gamification: princípios e estratégias”. São Paulo: Pimenta Cultural.

Hunicke, R., LeBlanc, M., Zubeck, R. (2004) "MDA: A formal approach to game design and game research". In: Proceedings of the AAAI Workshop on Challenges in Game AI.

Jorge, C. F. B.; Sutton, M. J. D. (2016) “Games como estratégia na construção e gestão do conhecimento no contexto da inteligência organizacional." Rev. Perspectivas em Gestão e Conhecimento, v.6, número especial, p.103-118.

Lisboa, C. P. (2017) "Uma experiência de orientação profissional no contexto de políticas públicas". Revista Brasileira de Orientação Profissional, v.18, n.1, p.105114.

Machado, Y.F. (2020) "A orientação profissional vivenciada a partir da gamificação". Dissertação (Mestrado em Educação Profissional e Tecnológica), Instituto Federal do Sertão Pernambucano, Salgueiro - PE, 2020, 184p.

Massi, M. L. G. (2017) "Criação de objetos de aprendizagem gamificadas para uso em sala de treinamento". Revista Científica Hermes, n.17, p.18-35.

Munhoz, I. M. S., Melo-Silva, L. L. e Audibert, A. (2016) "Educação para a carreira: pistas para intervenções na educação básica." In: Orientação vocacional e de carreira em contextos clínicos e educativos, organizado por Levenfus, R. S. Porto Alegre: Artmed.

Oliveira, V. S. (2016) “Orientação profissional na escola: possível relação entre teoria escolar e prática profissional”. Colloquium Humanarum, v. 13, n.2, p. 82-866.

Silva et al. (2017) "Anatomia Digital: Um ambiente virtual de apoio ao processo ensinoaprendizagem". In: Anais do Simpósio Brasileiro de Informática na Educação (SBIE), p. 745-755.

Silva, J. B., Sales, G. L., Castro, J.B. (2018) "Gamificação de uma sequência didática como estratégia para motivar a atitude potencialmente significativa dos alunos no ensino de óptica geométrica." In: Anais dos Workshops do Congresso Brasileiro de Informática na Educação, p.74-83. 
IX Congresso Brasileiro de Informática na Educação (CBIE 2020)

Anais do XXXI Simpósio Brasileiro de Informática na Educação (SBIE 2020)

Tavares V. L. C. (2009) "Orientação Vocacional e Profissional: um estudo sobre o funcionamento das estruturas de orientação nas escolas do Distrito de Braga." Tese de Doutorado - Universidade de Granada, p. 463.

Terçariol, A.A. L. et al. (2018) “A gamificação na pós-graduação: uma vivência com a concepção e a implementação de um minicurso em ambiente online." In: Anais do Congresso Internacional de Educação e Tecnologias - CIET:EnPED, p.1-8.

Zatti, F. et al. (2017) "Desenvolvimento de carreira de estudantes durante a graduação: análise de fundamentos epistemológicos em estudos nacionais.” Rev. Psicol., Organ. Trab., v. 17, n. 3, p. 150-158. 